\title{
Research on Model of Combine Trans-regional Operation Scheduling
}

\author{
Li Ma ${ }^{1}$, Meiqiong Ma ${ }^{1}$, Yanan Fan ${ }^{1}$, Yanjiao Zhang ${ }^{1}$ and Hongjie Zhao ${ }^{2}$ \\ ${ }^{1}$ College of Engineering, Northeast Agricultural University, Harbin 150030, \\ China \\ ${ }^{2}$ College of Science, Northeast Agricultural University, Harbin 150030, China \\ 1mwmary@163.com,Drizzlem19@163.com
}

\begin{abstract}
Unreasonable combine resource allocation has become one of the main factors influencing the economic benefits of trans-regional operation, so the scheduling strategy of combine trans-regional operation still needs to be further researched. On the basis of scheduling situation analysis of the order-oriented operation mode of agricultural machinery cooperation, this paper modelled the mathematical model of combine transregional operation scheduling with low cost and just in time as main targets. In modeling process, route optimization and workshop production scheduling theory were applied. Then, the idea of dynamic programming was used to carry out solution analysis of the model. Finally, this paper took an example of wheat trans-regional harvesting operation organized by an agricultural machinery cooperation of Hebei Province to verify the validity and feasibility of the model.
\end{abstract}

Keywords: Trans-regional operation; Scheduling model; Time window; Scheduling cost;

\section{Introduction}

Agricultural machinery trans-regional operation, a social service model of agricultural machinery, refers to the agricultural machineries carry out field harvesting operation cross above administrative regions of the county level according to the time difference of the crops mature period caused by vast territory and large difference of inter-regional climate of China. It is an efficient and economical service model with Chinese characteristics that can make the agricultural machinery more socialization and could solve the contradiction between small-scale peasant household management and mass production ${ }^{[1]}$. Trans-regional operation modes are various, according to different organizations the modes are divided into three kinds of modes, respectively operation mode of scattered machine household, organization mode of administrative departments and operation mode of intermediary organizations. At present, the most typical and extensive trans-regional operation mode is the order-oriented harvesting operation mode, and generally speaking, the organizers are the agricultural machinery cooperation ${ }^{[2]}$.

For the mode order-oriented harvesting operation, the core business of agricultural machinery cooperation is to organize agricultural machinery harvesting service, the business process is as follows: At the beginning of a year or a week before harvesting, the agricultural machinery cooperation sent personnel to contact the business and signed unified contract with the farmer's households to ensure work time, place, price, quality standard, arbitration, liability for breach of contract etc. At the time of signing the contract, according to total amount of agricultural machinery and operation ability in previous years, combined with the maintenance 
situation of the machine, the agricultural machinery cooperation carried out statistical analysis basis and predicted the harvest capacity of each combine this year to ensure a certain bottom line of orders. Then, the trans-regional operation service teams of combines were established to carry out harvesting service with a production team or a village as the basic unit. When an operation task was completed, the machinist signed the order with farmers (leaseholding households) to complete the contract, the dispute and other issues with the farmers would be solved by agricultural machinery cooperation. Finally, the total harvesting tasks were finished, the cooperation made settlement with customers by contract, and paid for the members of agricultural machinery cooperation according to the actual works ${ }^{[3]}$.

For combine trans-regional operation scheduling, how to arrange operation order and outfit combines for each operating point is the emphasis work of dispatchers ${ }^{[4]}$. The current scheduling situation is relying on artificial allocation and other traditional way to deploy combines. A dispatcher leads a small team to operate, who contacts with machinists by telephone to ascertain the status of job completion and the combines, and then dispatches the combines that have finished work nearby to another farmland ${ }^{[4]}$. We found agricultural machineries wasted most of time on fields' replacement due to the unreasonable arrangement of work order in this scheduling method, which not only reduced operation efficiency of combines, but also caused serious waste of oil, time and manpower and increased the cost. Meanwhile, it could delay harvesting time and led to orders can't be completed, which affected the economic benefits of trans-regional operation. In addition, the scheduling ignored the suitability of combines and farmlands. It needed to allocate different types of combines to ensure the quality of crops and operating costs according to the difference of the block shape, topography, land area and soil types etc.

The essence of combines trans-regional scheduling is the resource scheduling problem of combines and farmlands. Among them, the factors of time and space exist in the constraint form of time window and network topology, which makes combines trans-regional scheduling research more difficult. In 2006, Zhang Xiuhua planned walking routes of trans-regional operation, but didn't consider the harvesters equipment problem of operating points ${ }^{[5]}$. In 2006, Guo Pengtao regarded trans-regional scheduling as a transportation problem of operational research to solve, but did not consider operation start and end time ${ }^{[6]}$.In 2008, Li Hong et al. used graphic transformation method to convert agricultural machinery scheduling problem into multiple traveling salesmen problem with time windows, but failed to give full consideration to spatial topological relations of farms and harvesting points, especially when the work area is small, transfer time and cost of agricultural machineries can't be ignored ${ }^{[7]}$. In 2012, Zhang Fan established agricultural machinery deployment model based on machinery owners' choice, but the model only considered a kind of type and same operation capacity of agricultural machinery ${ }^{[8]}$. In 2013, Zhang Liguo established a mathematical model of agricultural machinery transportation and used table-manipulation method to get minimum transportation cost ${ }^{[9]}$. In 2013, Wang Yuwei regarded cotton-picker scheduling as a vehicle scheduling problem with time windows and designed a route for each cotton-picker, and each cotton field to be accessed once ${ }^{[10]}$. However, a cotton field could be accomplished by more machines in different time in the actual operation. In 2013, Wu Caicong abstracted the agricultural machinery scheduling model based on time windows ${ }^{[11]}$. However, the nature of the machines, transfer cost, transfer time and other variables were simplified and assumed in modeling process, which may reduce the calculation accuracy of the model. 
In summary, the research on scheduling problem of combine trans-regional operation isn't perfect. On the basis of existing research, this paper modelled the mathematical scheduling model of combine trans-regional operation with low cost and just in time as the main targets. In modeling process, route optimization and workshop production scheduling theory were applied, which regarded operating points as work pieces, harvesters as movable processing stations. Meanwhile, according to timely harvest date of crop, the thinking of JIT was used to analyze the operation start and end time of each operating point.

\section{The Establishment of Scheduling Model}

\subsection{Problem Description}

The scheduling problem of combine trans-regional operation can be described as: In a time period $\mathrm{T} 1-\mathrm{T} 2$, the agricultural machinery cooperation with a certain quantity of combines receives a number of trans-regional operation orders, the agricultural machinery cooperation needs to organize trans-regional operation teams to set out from a same place to provide harvesting services for customers in different regions. Each order has a time window and the job positions, block shape, area, available harvesters and the distances between operating points are known. So combine trans-regional operation scheduling problem is described as: For a series of farmlands to be operated, under the conditions of considering machine requirement and time windows of operating points, the dispatchers need to arrange appropriate traveling route for combines so that they pass through the farmlands and work in an orderly manner to achieve the effect of maximum benefit, minimum total cost or minimum travel distance. At the same time the each operation task of the farmland was completed within the specified time window ${ }^{[12]}$.

\subsection{Assumptions}

(1) In a certain period of time, crops are mature and reach the harvest conditions, the farmers put forward the earliest start and the latest end harvest time for transregional operation team. The combines must work for farmland within the time window, arriving ahead of the start time need to wait; more than the latest time, the job is considered invalid.

(2) The task of each operating point can be divided, namely one operation point may be serviced by one or more harvesters, and a harvester also can work for many operation points. Different operation points may be serviced by different combinations of harvesters at different moments.

(3) For the scheduling model of combine trans-regional operation, the time is composed of two parts: transportation scheduling time of combines and work time in each operating point.

(4) The demand number of combines for each operating point is uncertain, if the combines achieve a farmland earlier, the demand quantity of combines may be less, if relatively late, and then the point may need more combines to complete the task.

(5) The model and harvesting capacity of the harvester can meet the demand of peasant households' orders; the combine type which is suitable for each operation point can be known. Meanwhile, the machines can travel at a constant speed in the process of transportation and harvesting. 


\subsection{Variable Description}

(1) Parameters:

$N$ : The number of combine type;

$m_{\mathrm{i}}$ : The number of each type;

$M$ : Total number of combines;

$Q_{i}$ : Operating capacity of unit time of each type combine;

$Q$ : Total operating capacity of unit time of total combines;

$n$ : The number of operation points;

$j, k$ : The sequence number of operation points, $j, k=1,2, \ldots n$;

$S_{j}$ : The area of farmland $j$;

$C_{h j}$ : The scheduling cost of unit distance from point $h$ to point $j$;

$C_{i}$ : The operation cost of unit time of each type combine;

$C$ : The waiting cost of unit time of each harvester;

$N_{j}$ : The available combine sets of operating point $j, N_{j} \subseteq\{1,2, \cdots, N\}$;

$D_{(h, j)}:$ Distance from point $h$ to point $j$;

$V_{(h, j)}$ : Transport speed from point $h$ to point $j$;

$T_{(h, j)}$ : Transport time from point $h$ to point $j, T_{(h, j)}=\frac{D_{(h, j)}}{V_{(h, j)}} ;$

$\left[B_{\mathrm{j}}, E_{\mathrm{j}}\right]$ : The time window of operating point $j$, that is, the earliest start time and the latest completion time allowed by the point $j$;

$q_{j}$ : The minimum operating capacity of combines required to complete the task of point $j, q_{j}=\frac{S_{j}}{E_{j}-B_{j}}$

(2) Decision variables:

$x_{i_{k}(h, j)}$ : Whether the harvester $i_{k}$ works from point $h$ to point $j$;

$\left[b_{\mathrm{j}}, e_{\mathrm{j}}\right]$ : The actual time window of operating point $j$, that is the actual start time and completion time of point $j$;

$U_{i_{k} j}:$ The start time of harvester $i_{\mathrm{k}}$ at the operating point $j$;

$V_{i_{k} j}$ : The end time of harvester $i_{k}$ at the operating point $j$;

$F_{i_{k}}(j)$ : The actual operating time of harvester $i_{k}$ at the operating point $j$;

$A_{i_{k}(h, j)}$ : The arrival time of harvester $i_{k}$ from point $h$ to point $j$;

$Z_{i_{k}(h, j)}$ : Whether the arrival time of harvester $i_{k}$ from point $h$ to the point $j$ is earlier than the earliest start time allowed by the point $j$;

$L B_{j}$ : The latest start time of the operating point $j$.

\subsection{Construction of Model}

The combine trans-regional operation model of the paper is to study the orderoriented operation mode of agricultural machinery cooperation, in which total 
scheduling cost minimization as objective function shown in the formula (1). The total costs in objective function mainly include the transportation cost of combines, the work cost and the waiting cost of the early arrival at the farmland. In this model, the tasks of all the operating points are done within the time window range, so as to ensure the harvest punctuality and avoid crop losses caused by the delay harvesting or early harvest date.

$\operatorname{Min} \sum_{j=0}^{n} \sum_{h=0}^{n} \sum_{i=1}^{N} \sum_{k=1}^{m_{i}} x_{i_{k}(h, j)}\left(C_{(h, j)}+C_{i} F_{i_{k}}(j)\right)+\sum_{j=0}^{n} \sum_{i=1}^{N} \sum_{k=1}^{m_{i}} C x_{i_{k}(h, j)} Z_{i_{k}(h, j)}\left(B_{j}-Z_{i_{k}(h, j)}\right)$

Specific constraints are as follows:

The constraint (2) defines the number of combines deployed to the working point $j$ should not be more than the total available combines of point $j$;

$\sum_{h=0}^{n} \sum_{i=1}^{N} \sum_{k=0}^{m i} x_{i_{k}(h, j)} \leq M, i \in N_{j}$

(2)

The constraint (3) defines the sum of operating area of each agricultural machinery that participate in the task of operating point $j$ are equal to the total area of the farmland $j$;

$$
\sum_{h=0}^{n} \sum_{i=1}^{N} \sum_{k=0}^{m i} x_{i_{k}(h, j)} Q_{i} F_{i_{k}}(j)=S_{j}, i \in N_{j}, j, h=1, \cdots, n
$$

The constraint (4) defines the actual start time and end time of each operating point must be within the time window range;

$$
\left\{\begin{array}{l}
b_{j} \leq e_{j} \\
\mathrm{~B}_{j} \leq b_{j} \\
E_{j} \geq e_{j}
\end{array}\right.
$$

The formula (5) indicates that the actual completion time of operating point $j$ is equal to the latest end time of each combine at point $j$;

$e_{j}=\max \left\{V_{i_{k} j}\right\}, i \in N_{j}$

(5)

The formula (6) indicates that the actual start time of the operating point $j$ is equal to the earliest start time of each combine at point $j$;

$$
b_{j}=\min \left\{U_{i_{k} j}\right\}, i \in N_{j}
$$

The formula (7) indicates the actual working time of the combine $i_{k}$ at the operating point $j$.

$$
F_{i_{k} j}=V_{i_{k} j}-U_{i_{k} j}, i \in N_{j}, k \in m_{i}
$$

The formula (8) indicates the latest start time of the farm work; Because when all the available combines of point $j$ simultaneously arrive and work at point $j$ until all the tasks of point $j$ are completed before leaving, then the tasks of point $j$ will have the shortest completion time, we can calculate the latest start time point $j$ by the shortest completion time, the number and type of all the available combines of point $j$ and the end time allowed by the point $j$; 


$$
L B_{j}=E_{j}-\frac{S_{j}}{\sum_{i=1}^{N} Q_{i} m_{i}}+1, j=1,2, \cdots, n
$$

The constraint (9) defines the time from point $h$ to $j$ is less than or equal to the latest beginning service time of point $j$, which ensures the feasibility of the path; If the arrival time from point $h$ to $j$ is later than the latest beginning service time of point $j$, then the route form point $h$ to $j$ is invalid. Because if the arrival time later than the latest start time, even if all of the available combines work together at point $j$, the task of point $\mathrm{j}$ also can't be completed within the time window range.

$$
F_{i_{k}}(h)+T(h, j) \leq L B_{j}
$$

The formula (10) indicates that the arrival time of each combine from operating point $h$ to operating point $j$ is equal to the sum of the working time at point $h$ and the transporting time from $h$ to $j$;

$F_{i_{k}}(h)+T(h, j)=A_{i_{k} j}$

The constraint (11) uses 0-1variable to represent whether the combine $i_{k}$ works from $h$ to $j$; If the combine $i_{k}$ works from $h$ to $j$, then $x_{i_{k}(h, j)}=1$; if the combine $i_{k}$ doesn't work from $h$ to $j$, then $x_{i_{k}(h, j)}=0$; $x_{i_{k}(h, j)}=\left\{\begin{array}{l}1, \text { The harvester } i_{k} \text { worked from } h \text { to } j \\ 0, \text { The harvester } i_{k} \text { din't work from } h \text { to } j\end{array}\right.$

The constraint (12) uses 0-1variable to represent whether the arrival time from point $h$ to point $j$ of the combine $i_{k}$ is earlier than the start time allowed by point $j$; If the arrival time from point $h$ to point $j$ is later than the start time of allowed by point $j$, then $Z_{i_{k}(h, j)}=1$; If the arrival time from point $h$ to point $j$ is earlier than the start time of allowed by point $j$, then $Z_{i_{k}(h, j)}=0$;

$$
Z_{i_{k}(h, j)}=\left\{\begin{array}{l}
1, B_{j}-A_{i_{k}(h, j)}>0 \\
0, B_{j}-A_{i_{k}(h, j)} \leq 0
\end{array}\right\}
$$

The constraint (13) indicates the actual start time of each combine at point $j$ is determined by the arrival time. If combines arrive early, then they have to wait, the actual start time of each combine at point $j$ is equal to the start time allowed by point $j, U_{i_{k} j}=A_{i_{k}(h, j)}$; Otherwise, if combines arrive lately, then they can directly go to work, so the actual start time of each combine at point $j$ is equal to the arrival time, $U_{i_{k} j}=A_{i_{k}(h, j)}$;

$U_{i_{k} j}=\left\{\begin{array}{l}A_{i_{k}(h, j)}, Z_{i_{k}(h, j)}=0 \\ B_{j}, Z_{i_{k}(h, j)}=1\end{array}\right\}$

The constraint (14) indicates the total operating capacity of the available combines can meet the requirements of the point $j$. 


\section{Model Solving Analysis}

Scheduling is a combinatorial optimization problem with multiple objectives and multiple constraints, and its objective function is always associated with time order, resource allocation, and economic benefits etc. For this kind of scheduling model, the commonly used methods are intelligent algorithm and the scheduling algorithm based on rule, tectonic, and operations research. The optimal solution or approximate optimal solution can be obtained by these methods.

In the process of solving the model, the idea of dynamic programming was used to solve the scheduling problem. Firstly, the time constraint was considered, the initial operation period was cut into a finite time period. In each time period, according to the current state to complete a scheduling decision, and so on, the final scheduling scheme was completed (Figure1).

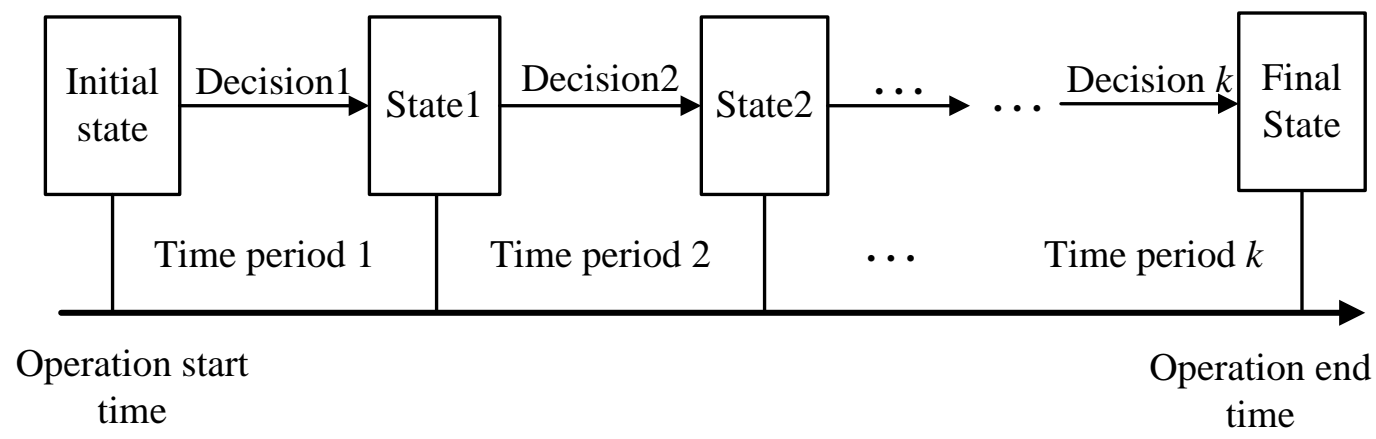

Figure 1. Decision Flow Chart

In each decision-making stage, only the combines and operation points participate in the scheduling process. In order to optimize the calculation process, using the following steps:

(1) From the point of combines, if a combine has already started work, check whether the operation point demand has been met; if not or the next decisionmaking stage doesn't need this type combine, then the combine will continue to work in this point and not participate in the scheduling decision.

(2) From the perspective of operating points, the operating points required to participate in the scheduling decision are chose and divided into two types: the operating points need to allocate the combines and add the combines.

(3) Integrated various cost factors, feasible path, available combine type of operating point, the combines and operating points to be dispatched are completed the optimal solution in accordance with the 0-1 assignment problem.

\section{Empirical Analysis of Model}

This paper carried out model test and application with wheat trans-regional harvesting operation organized by an agricultural machinery cooperation of Hebei. In trans-regional operating mode, the orders of a production team or village as a basic unit of contiguous operation, which is to ensure the harvest quality and speed. The location of the cooperation was referred as starting point $O$, combine type and quantity were illustrated in Table1, the information of time windows and operating area of each farmland point were shown in Table2, the locations of the agricultural 
machinery cooperation and each operating point were shown in Table3, the distances between the farmlands and starting point of combines in Table4. We set working hours of combines for 15 hours per day, transport speed of $30 \mathrm{~km} / \mathrm{h}$ in the scheduling process, the transport cost of a combine is $1 \mathrm{yuan} / \mathrm{km}$, and waiting cost of each combine is $30 y u a n / h$.

Table 1. Performance Table of Wheat Harvesters of the Cooperation

\begin{tabular}{ccccccccc}
\hline Type & Name & $\begin{array}{c}\text { Cutting } \\
\text { width(m) }\end{array}$ & $\begin{array}{c}\text { Power } \\
(\mathrm{kw})\end{array}$ & $\begin{array}{c}\text { Suitable } \\
\text { length }(\mathrm{m})\end{array}$ & $\begin{array}{c}\text { Suitable } \\
\text { area } \\
\left(\mathrm{hm}^{2}\right)\end{array}$ & $\begin{array}{c}\text { Number } \\
(\mathrm{car})\end{array}$ & $\begin{array}{c}\text { Capacity } \\
(\mathrm{mu} / \mathrm{h})\end{array}$ & $\begin{array}{c}\text { Cost } \\
\text { yuan/h } \\
)\end{array}$ \\
\hline A & John DeereL60 & $2.5 / 2.75$ & 59 & $\geq 400$ & $\geq 2$ & 5 & 9.75 & 92 \\
$\mathrm{~B}$ & LovolGF40 & $2.87 / 3.25$ & 73.5 & $\geq 400$ & $\geq 3$ & 5 & 9.75 & 98 \\
$\mathrm{C}$ & LovolGN70 & 4.57 & 125 & $\geq 600$ & $\geq 4$ & 4 & 13.5 & 110 \\
$\mathrm{D}$ & JohnDeereC230 & $4.57 / 5.34$ & 148 & $\geq 800$ & $\geq 5$ & 4 & 13.5 & 123 \\
\hline
\end{tabular}

Table 2. Farmlands Information of Orders

\begin{tabular}{ccccc}
\hline Order & Locaton & Area $(\mathrm{mu})$ & Option & Time window \\
\hline 1 & Haocheng & 50 & A.B & $6.1-6.2$ \\
2 & Anping & 478 & A.B.C.D & $6.3-6.6$ \\
3 & Xinle & 200 & A.B.C.D & $6.5-6.8$ \\
4 & Lixian & 360 & A.B.C.D & $6.9-6.11$ \\
5 & Anguo & 620 & A.B.C.D & $6.12-6.15$ \\
6 & Dingzhou & 62 & A.B.C & $6.16-6.17$ \\
7 & Gaoyang & 520 & A.B.C.D & $6.18-6.22$ \\
8 & Quyang & 603 & A.B.C.D & $6.21-6.25$ \\
9 & Wangdu & 74 & A.B.C & $6.23-6.24$ \\
10 & Xushui & 500 & A.B.C.D & $6.25-6.29$ \\
\hline
\end{tabular}

Table 3.The Specific Location of Each Operating Point

\begin{tabular}{cccc}
\hline Operating Point & Locaton & longitude & latitude \\
\hline$O$ & Xinji & 115.12 & 37.45 \\
1 & Haocheng & 114.5 & 38.02 \\
2 & Anping & 115.52 & 38.23 \\
3 & Xinle & 114.41 & 38.2 \\
4 & Lixian & 115.57 & 38.48 \\
5 & Anguo & 115.2 & 38.24 \\
6 & Dingzhou & 115 & 38.3 \\
7 & Gaoyang & 115.78 & 38.68 \\
8 & Quyang & 114.7 & 38.62 \\
9 & Wangdu & 115.15 & 38.72 \\
10 & Xushui & 115.65 & 39.02 \\
\hline
\end{tabular}

Table 4. The Distances between Farmland Points and Starting Point (unit: km)

\begin{tabular}{cccccccccccc}
\hline & $O$ & 1 & 2 & 3 & 4 & 5 & 6 & 7 & 8 & 9 & 10 \\
\hline$O$ & 0.0 & 10.7 & 20.6 & 31.2 & 43.8 & 56.5 & 63.4 & 76.5 & 89.0 & 100.2 & 126.5 \\
1 & 10.7 & 0.0 & 12.5 & 24.2 & 30.2 & 40.3 & 54.3 & 48.9 & 65.7 & 45.6 & 72.1 \\
2 & 20.6 & 12.5 & 0.0 & 51.4 & 18.6 & 26.5 & 64 & 19.4 & 28.3 & 89.0 & 45.0 \\
3 & 31.2 & 24.2 & 51.4 & 0.0 & 31.0 & 18.9 & 78.6 & 36.0 & 18.2 & 4.9 & 12.7 \\
4 & 43.8 & 30.2 & 18.6 & 31.0 & 0.0 & 25.9 & 31.2 & 25.0 & 93 & 59.1 & 38.6 \\
5 & 56.5 & 40.3 & 26.5 & 18.9 & 25.9 & 0.0 & 5.0 & 6.3 & 20.1 & 32.1 & 21.6 \\
6 & 63.4 & 54.3 & 64.0 & 78.6 & 31.2 & 5.0 & 0.0 & 32 & 19.6 & 88.9 & 43.1 \\
\hline
\end{tabular}




\begin{tabular}{cccccccccccc}
\hline 7 & 76.5 & 48.9 & 19.4 & 36.0 & 25.0 & 6.3 & 32.0 & 0.0 & 76 & 40.0 & 34.9 \\
8 & 89.0 & 65.7 & 28.3 & 18.2 & 93.0 & 20.1 & 19.6 & 76.0 & 0.0 & 19.3 & 45.7 \\
9 & 100.2 & 45.6 & 89.0 & 4.9 & 59.1 & 32.8 & 88.9 & 40.0 & 19.3 & 0.0 & 79.1 \\
10 & 126.5 & 72.1 & 45.0 & 12.7 & 38.6 & 21.6 & 43.1 & 34.9 & 45.7 & 79.1 & 0.0 \\
\hline
\end{tabular}

According to model solving steps of the last chapter, the paper used Matlab 2011 programing to achieve the solution of the mathematical model in the computer of Intel(R) Core(TM) i3-2370M CPU 2.40GHz, Memory2GB, and put the related variables data of trans-regional operation of the above example into the mathematical model. Finally, the optimal deploying scheme was obtained. Specific scheduling schemes for each operation point were shown in Table 5. The operating area of each combine at each operating point was shown in Table6. The operation sequence of each combine was shown in Table7. The convergence of the objective function (total scheduling cost) in the solving process is shown in Figure2.

Table 5. The Optimal Assignment Result of Combines and Operating Points

\begin{tabular}{|c|c|c|c|c|c|c|c|c|c|c|}
\hline $\begin{array}{l}\text { Farmland } \\
\text { Machine }\end{array}$ & 1 & 2 & 3 & 4 & 5 & 6 & 7 & 8 & 9 & 10 \\
\hline A1 & 1 & 1 & 1 & 0 & 1 & 0 & 1 & 0 & 1 & 0 \\
\hline A2 & 1 & 1 & 0 & 1 & 0 & 0 & 0 & 1 & 1 & 0 \\
\hline A3 & 0 & 1 & 0 & 0 & 0 & 1 & 0 & 0 & 0 & 0 \\
\hline A4 & 0 & 1 & 0 & 0 & 1 & 0 & 0 & 0 & 1 & 0 \\
\hline A5 & 0 & 0 & 0 & 1 & 1 & 1 & 1 & 0 & 0 & 0 \\
\hline B1 & 1 & 0 & 1 & 1 & 0 & 1 & 0 & 1 & 1 & 0 \\
\hline B2 & 0 & 0 & 0 & 0 & 0 & 1 & 0 & 1 & 1 & 1 \\
\hline B3 & 1 & 1 & 1 & 0 & 0 & 1 & 1 & 0 & 0 & 1 \\
\hline B4 & 0 & 0 & 0 & 0 & 1 & 1 & 1 & 0 & 0 & 0 \\
\hline B5 & 0 & 1 & 0 & 0 & 1 & 0 & 0 & 0 & 0 & 1 \\
\hline $\mathrm{C} 1$ & 1 & 0 & 0 & 1 & 1 & 1 & 0 & 1 & 0 & 1 \\
\hline $\mathrm{C} 2$ & 1 & 0 & 1 & 1 & 0 & 1 & 0 & 0 & 0 & 1 \\
\hline $\mathrm{C} 3$ & 0 & 1 & 0 & 0 & 0 & 0 & 0 & 1 & 0 & 1 \\
\hline $\mathrm{C} 4$ & 0 & 0 & 1 & 0 & 1 & 0 & 0 & 1 & 0 & 1 \\
\hline D1 & 1 & 0 & 0 & 0 & 0 & 0 & 0 & 0 & 0 & 0 \\
\hline D2 & 1 & 1 & 0 & 0 & 0 & 1 & 1 & 0 & 1 & 1 \\
\hline D3 & 1 & 1 & 1 & 1 & 0 & 1 & 1 & 0 & 1 & 1 \\
\hline D4 & 0 & 1 & 0 & 1 & 1 & 1 & 1 & 0 & 1 & 1 \\
\hline
\end{tabular}

In Table5, the 0-1 variable is used to represent the assignment of the harvester s and the operating points. If the corresponding relationship variable between the harvester A1 and the operating point 1 is 1 , then it represents the harvester A1 is arranged to work at the operating point 1 ; if the corresponding variable is 0 , then harvester A1 doesn't serve for the operating point 1 . we can see that the machines servicing for the operating point 1 are $\mathrm{A} 1, \mathrm{~A} 2, \mathrm{~B} 1, \mathrm{~B} 3, \mathrm{C} 1, \mathrm{C} 2, \mathrm{D} 1, \mathrm{D} 2, \mathrm{D} 3$; the machines servicing for the operating point 2 are A1, A2, A3, A4, B3, B5, C3, D2, D3, D4; the machines servicing for the operating point 3 are A1, B1, B3, C2, C4, D3; the machines servicing for the operating point 4 are A2, A5, B1, C1, C2, D3, $\mathrm{D} 4$; the machines servicing for the operating point 5 are $\mathrm{A} 1, \mathrm{~A} 4, \mathrm{~A} 5, \mathrm{~B} 4, \mathrm{~B} 5, \mathrm{C} 4$, D4; the machines servicing for point 6 are A3, A5, B1, B2, B3, B4, C1, C2, D2, D3, D4; the machines servicing for point 7 are A1, A5, B3, B4, D2, D3, D4; servicing for point 8 are A2, B1, B2, C1, C3, C4; the machines servicing for point 9 are A1, $\mathrm{A} 2, \mathrm{~A} 4, \mathrm{~B} 1, \mathrm{~B} 2, \mathrm{D} 2, \mathrm{D} 3, \mathrm{D} 4$; the machines servicing for point 10 are B2, B3, B5, $\mathrm{C} 1, \mathrm{C} 2, \mathrm{C} 3, \mathrm{C} 4, \mathrm{D} 2, \mathrm{D} 3, \mathrm{D} 4$. The number of machines servicing for operating point 6 is the most, for 11; The number of machines servicing for operating point 3 and 8 is the fewest, for 6 . 
Table 6. The Operating Area of Each Harvester at the Corresponding Farmland (Unit : Mu)

\begin{tabular}{|c|c|c|c|c|c|c|c|c|c|c|}
\hline Machine & 1 & 2 & 3 & 4 & 5 & 6 & 7 & 8 & 9 & 10 \\
\hline $\mathrm{A} 1$ & 2.21 & 42.08 & 14.43 & 0.00 & 102.50 & 0.00 & 75.13 & 0.00 & 10.96 & 0.00 \\
\hline $\mathrm{A} 2$ & 8.83 & 82.84 & 0.00 & 13.50 & 0.00 & 0.00 & 0.00 & 3.85 & 13.26 & 0.00 \\
\hline A3 & 0.00 & 79.56 & 0.00 & 0.00 & 0.00 & 6.05 & 0.00 & 0.00 & 0.00 & 0.00 \\
\hline A4 & 0.00 & 28.27 & 0.00 & 0.00 & 24.88 & 0.00 & 0.00 & 0.00 & 9.18 & 0.00 \\
\hline A5 & 0.00 & 0.00 & 0.00 & 38.25 & 57.72 & 10.82 & 86.95 & 0.00 & 0.00 & 0.00 \\
\hline B1 & 4.68 & 0.00 & 76.72 & 3.38 & 0.00 & 4.26 & 0.00 & 59.72 & 8.04 & 0.00 \\
\hline B2 & 0.00 & 0.00 & 0.00 & 0.00 & 0.00 & 3.83 & 0.00 & 163.75 & 1.57 & 51.30 \\
\hline B3 & 0.88 & 26.96 & 11.15 & 0.00 & 0.00 & 3.58 & 94.55 & 0.00 & 0.00 & 70.75 \\
\hline B4 & 0.00 & 0.00 & 0.00 & 0.00 & 115.44 & 9.71 & 32.08 & 0.00 & 0.00 & 0.00 \\
\hline B5 & 0.00 & 47.34 & 0.00 & 0.00 & 97.53 & 0.00 & 0.00 & 0.00 & 0.00 & 53.66 \\
\hline $\mathrm{C} 1$ & 9.28 & 0.00 & 0.00 & 30.38 & 84.59 & 6.81 & 0.00 & 204.21 & 0.00 & 23.58 \\
\hline $\mathrm{C} 2$ & 7.77 & 0.00 & 66.89 & 46.13 & 0.00 & 7.07 & 0.00 & 0.00 & 0.00 & 74.29 \\
\hline $\mathrm{C} 3$ & 0.00 & 50.63 & 0.00 & 0.00 & 0.00 & 0.00 & 0.00 & 167.61 & 0.00 & 46.58 \\
\hline $\mathrm{C} 4$ & 0.00 & 0.00 & 19.67 & 0.00 & 34.83 & 0.00 & 0.00 & 1.93 & 0.00 & 41.27 \\
\hline D1 & 4.06 & 0.00 & 0.00 & 0.00 & 0.00 & 0.00 & 0.00 & 0.00 & 0.00 & 0.00 \\
\hline D2 & 6.63 & 11.83 & 0.00 & 0.00 & 0.00 & 4.77 & 79.35 & 0.00 & 8.56 & 64.86 \\
\hline D3 & 5.57 & 60.49 & 10.49 & 120.38 & 0.00 & 0.94 & 81.04 & 0.00 & 11.79 & 62.50 \\
\hline D4 & 0.00 & 47.34 & 0.00 & 106.88 & 101.51 & 4.09 & 70.06 & 0.00 & 10.54 & 10.61 \\
\hline
\end{tabular}

Table 6 shows the operating area of each combine at each operating point. From Table 6 , we can see that the total operating areas of the combine A1, A2, A3, A4, A5 respectively are $247.31,122.29,85.6,207.89,193.73$; the total operating areas of the combine B1, B2, B3, B4, B5 respectively are 156.8, 350.53, 207.87, 157.23, 365.09; the total operating areas of the combine $\mathrm{C} 1, \mathrm{C} 2, \mathrm{C} 3, \mathrm{C} 4$ respectively are $358.85,202.15,561,97.7$; the total operating areas of the combine D1, D2, D3, D4 respectively are $4.06,101.77,353.19,351.03$. In which, the total operating area of combine $\mathrm{C} 3$ is the most, for $561(\mathrm{Mu})$, the total operating area of combine D1 is the fewest, for $4.06(\mathrm{Mu})$.

Table 7. The Optimal Job Orders of Farmlands in Corresponding Combines

\begin{tabular}{ccccccc}
\hline Machine & \multicolumn{7}{c}{ Job order } \\
\hline A1 & 5 & 9 & 2 & 1 & 3 & 7 \\
A2 & 8 & 9 & 2 & 1 & 4 & \\
A3 & 2 & 6 & & & & \\
A4 & 3 & 9 & 5 & & & \\
A5 & 7 & 4 & 5 & 6 & & 6 \\
B1 & 1 & 4 & 3 & 9 & 8 & \\
B2 & 9 & 8 & 6 & 10 & & 6 \\
B3 & 10 & 1 & 3 & 2 & 7 & \\
B4 & 5 & 6 & 7 & & & \\
B5 & 2 & 10 & & & & \\
C1 & 8 & 10 & 5 & 4 & 1 & \\
C2 & 6 & 1 & 10 & 4 & 3 & \\
C3 & 10 & 2 & 8 & & & \\
C4 & 10 & 8 & 5 & & & \\
D1 & 1 & & & & & \\
D2 & 2 & 9 & 10 & 6 & 1 & 7 \\
D3 & 3 & 9 & 1 & 4 & 10 & 7 \\
D4 & 7 & 2 & 9 & 10 & 4 & 5 \\
\hline
\end{tabular}


Table 7 gives the optimal operation sequence of each combine serving for operating points in detail, in which the optimal operation sequence of the combine A1, A2, A3, A4, A5 at corresponding operating points respectively are point 5-9-21-3-7, point 8-9-2-1-4, point 2-6, point 3-9-5, point 7-4-5-6; The optimal operation sequences of combine B1, B2, B3, B4 respectively are point 1-4-3-9-8-6, point 9-86-10, point 10-1-3-2-7-6, point 5-6-7, point 2-10; The optimal operation sequences of combine $\mathrm{C} 1, \mathrm{C} 2, \mathrm{C} 3, \mathrm{C} 4$ respectively are point 8-10-5-4-1-6, point 6-1-10-4-3, point 10-2-8, point 10-8-5; The optimal operation sequences of combine D1, D2, D3, D4 respectively are point 1 , point 2-9-10-6-1-7, point 3-9-1-4-10-7-6-2, point 7$2-9-10-4-5-6$. The field number worked by combine D3 is the most, for 9 . The field number worked by combine D1 is the fewest, combine D1 only works at operating point 1.

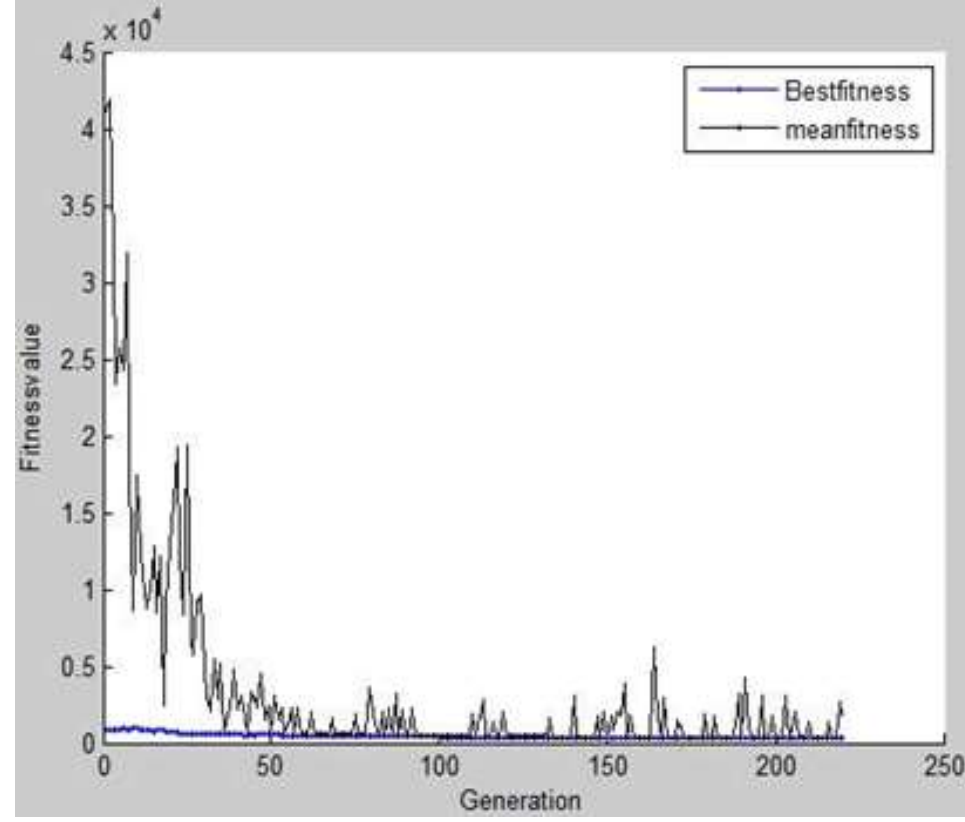

Figure 2. The Convergence Graph of Optimal Solution

From Figure 2 we can see the whole convergence of the objective function in the process of solving the model. When the iteration number is 220 , the value of the objective function is the optimal. Therefore, for the case of wheat trans-regional harvesting operation organized by an agricultural machinery cooperation of Hebei, the optimal value of total scheduling cost is \$4275.19. Obviously, using the mathematical mode in this paper to solve scheduling problem of combine transregional operation can obtain a better result. And the mode provides a scientific and effective deployment scheme for the management department of combine transregional operation, it has a certain practical application and research value.

\section{Conclusions}

Under the premise of considering time widow and space factor, this paper had modeled the mathematical model of combine trans-regional operation scheduling to study the order-oriented and trans-regional operation mode of agricultural machinery cooperation, in which total scheduling cost minimization as the objective function. The total cost in objective function mainly included the transportation cost of the combines, the work cost and the waiting cost of the early arrival at the farmland. In addition, the mathematical scheduling model was to ensure the timeliness of combine trans-regional operation, the task of each operating point 
could be completed on time within the time window. Meanwhile, in the process of model solution, the problem was divided into several decision-making stages according to the initial operation period to solve the optimal scheduling scheme. The final experiment results showed the model can achieve rapid deployment of agricultural machinery and can provide a reasonable and valid deploying scheme for trans-regional operation organization.

\section{Acknowledgements}

The research is funded by the sub-item of agro-scientific research in the public interest ( 201503116-04-01 ).

\section{References}

[1] W. Man, "Research on System Optimization of Cross Region Work in Hebei Province", HeBei University, (2014).

[2] S. Xinagli, "Study on the Effect Factor on Choice among Organization Model for Combine Make Across Service in North of Jiangsu Province", Nanjing Agricultural University, (2009).

[3] C. Gunagqiao and Z. Zongyi, "Report of Agricultural Machinery Trans-Regional Operation in Hebei", Shangdong, Henan, Jiangsu and Anhui, Journal of Agricultural Mechanization Research, vol. 6, (2007), pp. $1-4,8$.

[4] L. Xiaolian and G. Yingwu, "Development Situation and Prospect about Cross-Region Harvest Task", Journal of Agricultural Mechanization Research, vol. 2, (2008), pp. 10-14.

[5] Z. Xiuhua, "Study on the Service System in Wheat Trans-regional Harvesting Using Combine", Beijing: Agricultural University of China, (2006).

[6] G. Hongpeng, "Study on the Decision Support System of Contract Hire System of Agricultural Machines in China", Journal of Agricultural Mechanization Research, vol. 2, (2006), pp. 39-42.

[7] W. Zhuang, C. Liping and L. Yongsheng, "Design and Implementation of Agricultural Machinery Monitoring and Scheduling System", Computer Engineering, vol. 36, no. 11, (2010), pp. 232-234, 237.

[8] Z. Liguo, "The Application of Table-Manipulation Method in Agricultural Machinery Scheduling", Agricultural Machinery, vol. 6, (2013), pp. 178-179.

[9] Z. Fan, T. Guifa and M. Jianbin, "Farm Machinery Scheduling and Allocating Based On Heuristic Priority Rules", Transactions of the Chinese Society of Agricultural Engineering, vol. 28, no. 10, (2012), pp. 78-85.

[10] W. Yuwei, "Cotton-picker Cross-Regional Scheduling Algorithm Research and Implementation", Shihezi University, (2013).

[11] W. Caicong and C. Yaping, "Time-windows Based Temporal and Spatial Scheduling Model for Agricultural Machinery Resources", Agricultural Machinery Journal, vol. 5, (2013), pp. 237-241, 231.

[12] L. R. Foulds and J. M. Wilson, "Scheduling Operations For The Harvesting of Renewable Resources", Journal Of Food Engineering, vol. 70, (2005), pp. 281-292.

[13] C. B. Basnet, L. R. Foulds and J. M. Wilson, "Scheduling Contractors' Farm-to-Farm Crop Harvesting Operations", International Transactions in Operational Research, vol. 13, no. 1, (2006), pp. 1-15.

[14] O. Ali and D. Van Oudheusden, "Infield Logistics Planning for Harvest Operations", Proceedings of the ELA Doctoral Workshop.

[15] L. R. Foulds, "Hay Harvesting Operations Scheduling Subject to Probabilistic Activity Duration and Machine Failure".

[16] D. Bochtis and S. Van Ougioukas, "Field Operation Planning for Agricultural Vehicles: A Hierarchical Modeling Framework", Agricultural Engineering International: the CIGR Ejournal, vol. 6, no. 21, (2007).

[17] S. Guan, M. Nakamura and T. Shikanai, "Resource Assignment and Scheduling Based On a Two-Phase Metaheuristic for Cropping System”, Computers and Electronics in Agriculture, vol. 66, (2009), pp. $181-190$

[18] I. A. Chaudhry, "Job Shop Scheduling Problem with Alternative Machines Using Genetic Algorithms", Journal of Central South University, vol. 5, (2012), pp. 1322-1333.

[19] A. Gorbenko and V. Popov, "Task-resource Scheduling Problem”, International Journal of Automation \&amp; Computing, vol. 4, (2012), pp. 429-441.

[20] Z. Yan, G. Hanyu and X. Yugeng, "Modified Bottleneck-Based Heuristic for Large-Scale Job-Shop Scheduling Problems with A Single Bottleneck", Journal of Systems Engineering and Electronics, vol. 3 , (2007), pp. 556-565. 
[21] L.-Y. Deng, Y. Lin and M. Chen, "Hybrid ant colony optimization for the resource-constrained project scheduling problem", Journal of Systems Engineering and Electronics, vol. 1, (2010), pp. 67-71.

[22] A. Jamili, "Robust Job Shop Scheduling Problem: Mathematical Models", Exact and Heuristic Algorithms. Expert Systems with Applications, vol. 55, (2016), pp. 341-350.

[23] S. Gholizadeh-Tayyar, L. Dupont and J. Lamothe, "Modeling a Generalized Resource Constrained Multi Project Scheduling Problem Integrated with a Forward-Backward Supply Chain Planning", International Federation of Automatic Control, vol. 9, no. 12, (2016), pp. 1283-1288. 
International Journal of Grid and Distributed Computing

Vol. 10, No. 1 (2017) 